\title{
Low Salinity as New Technique of Enhanced Oil Recovery
}

\author{
Adam Abdalla, Renyuan Sun, Tang Guiyun, Aixian Huang, and Meijie Wang
}

\begin{abstract}
Low salinity water flooding is a very promising EOR method in recent years in which chemistry play major role in improving oil recovery. Several studies shown that oil recovery significantly increase by low salinity water flooding (LSWF) in sandstone. However, the mechanisms of oil recovery improvement are still controversial, its considered to be decrease of residual oil saturation and alteration of rock wettability, the solution and surface chemistry as well as rock/fluid interactions have important roles that can be attributed to reservoir minerals being sensitive to small changes in solution properties. This paper provides a comprehensive review of low salinity water flooding. Attempt is made to cover all aspects and features of low salinity water flooding to shed light on critical and challengeable features and clear the gaps and deficiencies of conducted studies. The proposed mechanisms are discussed and their success and failure are explained. Analytical and numerical modeling of low salinity water flooding is presented. Secondary and tertiary low salinity water flooding are compared in the term of additional oil recovered. Surfaces forces and rock/fluid/brine interaction and its relationship to wettability are discussed. Results of combined low salinity and EOR methods are described which includes simultaneous use of low salinity with polymer flooding, surfactant flooding. Accordingly, low salinity water flooding EOR methods have great potential for enhanced oil recovery in the future.
\end{abstract}

Index Terms-Low salinity water flooding, oil recovery, secondary recovery, tertiary recovery.

\section{INTRODUCTION}

With the decline of recovery from conventional oil reservoirs and limitations of finding new conventional oil pools, petroleum researchers are now focusing on new lowcost, environmentally friendly Enhanced Oil Recovery techniques for sweeping the residual oil left behind by secondary and tertiary recovery. Low saline water flooding is an EOR technique in which, by decreasing the injection water salinity $(1,000-5,000 \mathrm{ppm})$ and choosing the specific ionic composition, residual oil saturation can be diminished by a significant amount in the tertiary recovery stage and more importantly, in the secondary recovery stage in the early life of a reservoir [1].

Low salinity water flooding is a newly developed EOR technique in which chemistry play major role in improve oil recovery, it has been proposed that the concentration of salt

Manuscript received November 15, 2016; revised March 10, 2017.

Adam Abdalla, Renyuan Sun, and Tang Guiyun are with School of Petroleum Engineering, China University of Petroleum, China (e-mail: Adamabdalla2015@gmail.com, sunrenyuan@126.com).

Aixian Huang is with Dongxin Oil Production Plant, Shengli Oilfield Company, SINOPEC, Dongying, Shandong, China.

Meijie Wang is with Research Institute of Engineering \&Technology, Xinjiang Oilfield Company, CNPC, kelamayi, Xinjiang, China. ions in the injection brine can increase the oil recovery but the biggest challenge of low salinity injection is to understand how this process works in the oil production process because the mechanisms have not yet been verified, the solution and surface chemistry as well as rock/fluid interactions have important role that can be attributed to reservoir minerals being sensitive to small changes in solution properties [2], [3]. The performance of a water flooding is typically affected by the following main parameters: reservoir geology and geometry, physical properties, porosity, permeability, heterogeneity, fluid properties: viscosity, mobility ratio, mineralogical properties: clay type and amount. Over decades much research has been done to optimize these parameters to be able improve water flooding process [4]. The effect of water chemistry on brine-rock interactions was seldom paid any attention, even though the effect of low salinity brine in sandstone rock containing clay was revealed in the 60's.

In recent years controlling the salinity and composition of the injected water has become an emerging enhanced oil recovery technique, often described as low salinity water flooding. Modification of the water composition has shown to be an excellent way to increase recovery from both sandstone and carbonates. Many researchers have reported, both in field and laboratory test, increase in oil recovery by LS flooding. The complexity and amount of parameters behind oil/brine/rock interactions are thought to be the reason.

\section{Different Mechanisms That Have Been Proposed}

Since 1990, some mechanisms for LSWF efficiency have been proposed. Among these mechanisms, three mechanisms are more acknowledged which are as follows.

Tang and Morrow [3] claimed that particle release during low salinity injection occurred. These release particles are mixed-wet and, by their migration out of the core, they can transport the attached oil drops and improve the recovery. As these mixed-wet particles separate from the pore surface, the water-wet underlying surface is exposed to the fluids. This will in turn increase the rock water wetness.

Mc Guire [5] claimed that a PH increase during LSWF was the main reason of oil recovery improvement. The presented that as low salinity water was injected, hydroxyl ions were generated through reactions with native minerals of the reservoir and thus $\mathrm{PH}$ increased from 7 to 8 ; it might rise up to a $\mathrm{PH}$ of 9 or even more. As a result, they compared low salinity water behavior with alkaline flooding. Like alkaline flooding, low salinity water reduced the interfacial tension between the reservoir oil and water and $\mathrm{PH}$ elevation tended to make the rock more water-wet and 
hence improve oil recovery. Furthermore, low salinity water resulted in the alteration of crude oil properties. When oil contacted high PH low salinity water, the acid or polar components in the oil were saponified, which was basically an in-situ surfactant.

This mechanism considers bridging negatively-charged oil to the clay minerals by multivalent cations [2]. Larger [6] provided evidence that multicomponent ion exchange (MIE) occurred during LSWF and improved oil recovery. They revealed that MIE occurred between rock, oil and brine and by some procedure detached the oil from rock surface which resulted in oil recovery improvement.

Polar components are saponified due to contact with raised $\mathrm{PH}$ and act as surfactant. Beside these the hardness ions such as calcium and magnesium will precipitate the surfactants in high salinity water injection, hence prevent increasing oil recovery.

Mechanism of oil/brine/mineral interaction:

Buckley and Liu [7] argued four ways of oil/ brine/ mineral interactions by which wettability is governed.

Polar interaction: This interaction takes place between polar functional group of oil and polar surface sites if mineral under clean and dry surface conditions.

Surface precipitation: If the oil does not have high level of solubility for the asphaltenes, the system trend for wetting alteration increases.

Acid/base interactions: In the presence of water, Polar functional groups of both mineral and crude oil phases can behave as acids and bases creating charges in both the solid and oil interface. $\mathrm{PH}$ is the main governing factor of the level of surface charge.

Ion-binding interactions: The ions such as $\mathrm{Ca}^{2+}$ can acts as a bridge making three possible interactions. Oil-Ca-oil, mineral- Ca-mineral and Oil-Ca-mineral. The first two can limit wettability alteration while the last promotes it. $\mathrm{PH}$ is not the essential factor and temperature is supposed to affect interactions greatly.

In an oil/brine/rock system, more than one interaction occurs. Surface precipitation is less likely to take place due to usual presence of water as first fluid occupying the pore space. Roughly, combination of three properties, API gravity (solvent quality of the oil) acid and base numbers give a qualitative index for wetting alteration. But experimental study by Basu and Sharma showed that polar components (resin and asphaltens) play an important role in disjoining pressure of brine film between mineral and oil. In presence of resin and asphaltens, film stability decreases with increasing brine salinity and decreasing of $\mathrm{pH}$ while without them increasing the $\mathrm{pH}$ and salinity leads to more stable film. The later consequence was not in agreement with calculation of DLVO theory as authors suggested the role of variation of hydrophobic force with salinity.

\section{NECESSARY CONDITION FOR LOW SALINITY IMPROVE OIL RECOVERY}

Based on systematic experiment by Tang and Morrow [3] the necessary condition to observe low salinity oil recover enhancement:

Porous Media: clay must be present.

Oil: must contain polar components (acids and bases)
Water: formation water (FW) must contain divalent cations $\left(\mathrm{Ca}^{2+}, \mathrm{Mg}^{2+}\right)$ [1]. Initial $\mathrm{FW}$ must be present, Low Salinity fluid (salinity: 1000-2000 ppm).

As a general rule, it can be stated that presence of clay is essential for a formation to have potential of low salinity water flooding. Although there is exception for this rule. It's observed that incremental oil recovery is function of percentage of formation clay.

\section{HOW DOES LOW SALINITY WORK?}

Oil molecules bind to clay particles by bridges of divalent cations such as; $\mathrm{Ca}^{++}, \mathrm{Mg}^{++}[2]$.

In a high Salinity water that is found in reservoir these bridges are compressed to the clay surface, by electrical forces, meaning that plenty of oil molecules are not free to flow.

By reducing the salinity of the water the bridges relax and able to expand, allowing non-bridging monovalent ions like $\mathrm{Na}+, \mathrm{K}+$ access and replace the divalent ions. This frees the oil molecules that can then be swept to the producing wells.

\section{Secondary Versus Tertiary Mode}

Both secondary and tertiary low salinity water flooding contribute to incremental oil recovery. But usually secondary injection is more desire, and in some conditions tertiary low salinity water injection didn't result extra oil recovery [8].

\section{WetTABILITY EFFECTS AND ITS ALTERATION}

It is believed that enhanced oil recovery in low salinity water flooding is related to wettability change. Furthermore, there is direct evidence that wettability altered to more water-wet during low salinity water flooding [9], [10]. Accordingly, initial and final wettability's are key indices which have been evaluated. However, results are controversial. The initial oil-wet is essential to observe low salinity effect [11], since water-wet sample produced no additional oil. The type and level of salinity water injection is important to create wettability of a reservoir. In presence of plagioclase mineral, higher salinity cause $\mathrm{PH}$ below 7 which in turn create mixed-wet condition which is favorable condition for low salinity water flooding. On the other hand, in moderate low salinity water injection this mineral causes PH7 which create unfavorable water-wet state [7]. The desired final wettability is also matter of debate. Some researchers reported that low salinity water flooding change the wettability into neutral state rather than water-wet state [8], [9]. Ashraf et al [4] pointed out same result.

\section{EFFECT OF BRINE COMPOSITION}

An extensive study by shell researcher [12] examined the role of formation composition and imbibing brine as well as type of crude oil in low salinity imbibition experiments. They found that presence of $\mathrm{Ca}^{2+}$ and $\mathrm{Mg}^{2+}$ in formation brine makes the sample more oil-wet and also the more $\mathrm{Ca}^{2+}$ and $\mathrm{Mg}^{2+}$ concentration in formation brine, the more oil-wet 
behavior the sample shows. And interesting finding was that the samples with high level of $\mathrm{Ca}^{2+}$ and $\mathrm{Mg}^{2+}$ when surrounded by high and low $\mathrm{NaCl}$ salinity exhibited same oil recovery.

\section{EFFECT OF/ON CORE MINERALOGY}

Presence of clay minerals is essential for having a good potential of low salinity water flooding. Review of 411 core flooding experiments revealed a strong correlation between residual oil saturation to chlorite and kaolinite contents and wettability index as well [13]. The experiments by Morrow confirmed this type of correlation. Low salinity water flooding changes the composition of cores and associated rock properties. Experimental study of pu et al. [14] showed the cores that are rich in anhydrite cement, low salinity water flooding dissolved the cements. Presence of sulphate ions in effluent water and thin section pictures confirmed this conclusion. However, it is not clear that is a cause, effect or accompany phenomenon. During low salinity water flooding permeability increase of $100 \%$ was happened [13]. On the other hand, $10 \%$ decrease of permeability was observed in case of 100 diluted water flooding.

\section{EFFECT OF TEMPERATURE}

Effect of temperature seems complicated. Flooding tests of samples from Varg field showed that low salinity waterflooding effect is observed when aging temperature was 90 $\mathrm{C}$ while no extra oil was recovered when aging temperature was 60 and $130 \mathrm{C}$ [14].

As well, impact of temperature showed varies from substantial impact on contact angle of crude oil with mica to non-significant in muscovite and biotite surfaces pre-treated with $\mathrm{pH} 4,[\mathrm{NaCl}]=0.1 \mathrm{M}$ brine Buckley [15].

Low salinity water-flooding illustrated more sensitive than high salinity water-flooding. Higher aging and flooding temperature resulted in higher oil recovery due to low salinity water-flooding compared to high salinity waterflooding [16].

\section{EFFECT OF LOW SALINITY ON INTERFACIAL TENSION}

Exploring the impact of salinity on interfacial tension is crucial since a mechanism is proposed by McGuire et al [5] indicating lower salinity water reduced IFT between water and oil which in turn enhances oil recovery. Water/oil interfacial tension is greatly affected by oil composition. Large number of components in crude oil makes difficult to predict IFT of water/oil. Buckley and Fan [13] measured the IFT of crude oil and made a correlation between IFT and some crude oil parameters. Based on statistical analysis, they proposed a correlation indicating higher amounts of nC7 asphaltenes, base number and viscosity of crude oil results in higher value of IFT. On the other hand, higher values of PH and acid number lead to lower value of IFT. Experimental study on dead oil of yate's field revealed that with dilution of the brine, the IFT decreased initially, but it increased by further dilution of brine. Accordingly, acritical salinity was recognized in which the IFT has the lowest value [13]. An optimum IFT (lowest value) in $5 \% \mathrm{NaCl}$ brine concentration also reported by Alotaibi and Nasr-ElDin [17].

Type of brine composition affects the IFT. Presence of $\mathrm{CaCl}_{2}$ increase the IFT compared to $\mathrm{NaCl}$ or formation brine composition [15].

\section{ANALYTICAL AND NumERICAL MODELLING}

Two approaches have been considered to model low salinity water flooding. In the first one, the mechanism of rock/oil/brine interaction is ignored and just relative permeability, capillary pressure or other main parameters are functioned on salinity concentration.

In this approach it is showed that modelling of low salinity water flooding can be considered same as other water flood-based EOR in which fractional flow equation should be modified to reach appropriate model for process [18].

$\mathrm{Wu}$ and Bai [19] modelled low salinity water flooding mathematically and numerically for both sandstone and fractured media. Salt was considered as a component transported and contained only in the aqueous phase. However, the salt can absorb on rock grains and transportation take place by advection and diffusion. Both relative permeability and capillary pressure were modelled as function of salinity that results in enhancement in oil recovery. The analytical equations were discretized to reach numerical formulation and were implemented in a general simulator MSFLOW. The simulator was matched successfully with experimental results.

Without considering the mechanism behind the process, [20] coupled UTECHEM and Iphreeqe simulators and tested it. To model wettability alteration relative permeability and capillary pressure are interpolated based on two sets of carves. UTECHEM was used for species transportation and Iphreeqe to find rock-fluid equilibrium state. Consequently, his relative permeability and capillary pressure curves are constructed.

In the second approach, rock/oil/brine (geochemical) interaction is modelled to results in wettability alteration which can be regarded as mechanistic model.

A numerical model that couples a Buckley-Leverett twophase model and multiple ion exchanges as the main mechanism of wettability [21]. The model is created for one dimensional low salinity water flooding suitable for lab experiments. The ions calcium, magnesium, and sodium can desorb or adsorb to the rocks that in turn determine the wettability and new relative permeability curves. The cations release depends on several factors such as clay content and connate water and injected brine composition.

\section{COMBINED EOR AND LOW SALINITY WATER FLOODING}

Combination of many EOR methods and low salinity water flooding can be considered to use their benefit simultaneously.

Of the advantage of surfactant low salinity water flooding are lower adsorption and retention and higher solubility of 
surfactant resulting better oil recovery and economic than only surfactant water flooding [22]. In the case of surfactant low salinity water flooding, intermediate-wet condition showed more favorable condition than the water-wet condition [23].

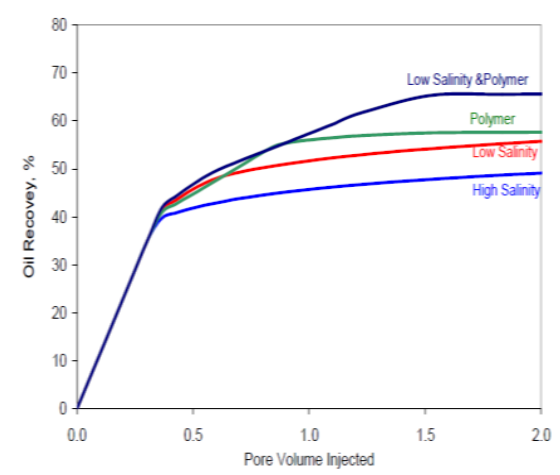

Fig. 1. Combination of polymer and low salinity water flooding.

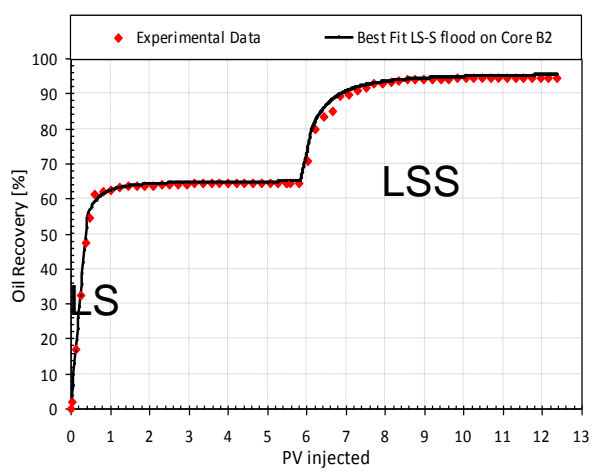

Fig. 2. Simulation of combined low salinity brine and surfactant flooding.

Combination of polymer and low salinity water flooding was examined by Mohammadi and Jerauld [24] numerically. They found that the combined method benefits equal the summation of each technique. In addition, the polymer low salinity flooding reduces the necessary amount of polymer somehow one-third of polymer flooding alone. In fact, low salinity condition increases viscosity of solution compared to high salinity condition making it more favorable for such process. Moreover, it reduces retention of polymer to rock. The same numerical study by Alzayer and Sohrabi [25] shows effectiveness of polymer low salinity water flooding for heavy oil recovery. Analyses of some experimental data were consistent with above statements [26]. Besides, the low salinity media, polymer is more stable at higher temperature and shear degradation. It also provides less production chemistry issue such as scaling and souring, these all reduce the expenditure for this process compared to conventional polymer flooding. On the opposite side, it causes some disadvantage such as clay swelling and breakthrough delay. Both sides should be considered in economics of the process [26].

Injection of polymer low salinity water in secondary mode (at initial water saturation) is more beneficial than tertiary (at residual oil saturation) mode [27].

\section{CONCLUSION}

The extent of the increase in oil recovery by low salinity water-flood is highly specific to crude oil-brine-rock interactions and cannot be predicted.

Type of clay and its concentration has a significant effect on wettability alteration.

Not all levels of low salinity can increase the oil recovery in sandstone reservoir. An optimum salinity level should not be exceeded to recover more oil.

The conducted researches in other fields such oil extraction from mined oil sands, underground water engineering, soil science, effluent environmental science, paper industry and those industries that clays play important roles can be useful to determine surface complexes and interactions.

Economic part of the process is important to evaluate the applicability of the process. Low salinity water flooding is same as water flooding in process except it has additional unit of desalination to reach proper salinity. Furthermore, environment issue due to release of high salinity water and process by-product sludge should be assessed.

Comprehensive studies are needed to cover all aspects of low salinity water flooding from atomic and droplet scales to reservoir scale to assess the EOR potential of low salinity water flooding. Such a workflow is sketched by Suijkerbuijk et al., [14] in three main levels. At single droplet scale the DLVO and non-DLVO forces in rock/brine/oil system should be considered. Channel scale study is needed to quantify hydrodynamics of the process. At the end reservoir scale couple geochemical processes with two-phase flow processes.

\section{NOMENCLATURE}

LSW low salinity water flooding

HSW high salinity water flooding

MIE multi component ion exchange

API American petroleum institute, gravity (solvent quality of the oil)

DLVO (Deryaguin-Landau-Verwey-Overbeek) theory IFT Interfacial Tension

\section{REFERENCES}

[1] Bernard, "Effect of floodwater salinity on recovery of oil from cores containing clays," in Proc. $38^{\text {th }}$ Annual California Regional Meeting of the Society of Petroleum Engineers, California, USA, 1967.

[2] J. S. Buckley, K. Takamura, and N. R. Morrow, "Influence of electrical surface charges on the wetting properties of crude oils," SPE Reservoir Engineering, vol. 4, no. 3, pp. 332-240, August 1989.

[3] G. Q. Tang and N. R. Morrow, "Influence of brine composition and fines migration on crude Oil/brine/rock interactions and oil recovery," Journal of Petroleum Science and Engineering, vol. 24, pp. 99-111, 1999.

[4] A. Ashraf, N. Hadia, O. Torsaeter, and M. T. Tweheyo, "Laboratory investigation of low salinity water flooding as secondary recovery process: Effect of wettability," in Proc. SPE Oil and Gas India Conference and Exhibition, 20-22 January, 2010.

[5] P. McGuire, "Low salinity oil recovery: An exciting new eor opportunity for Alaska's North slope," in Proc. SPE Western Regional Meeting, Irvine, CA, USA, 2005.

[6] A. Lager, "Low salinity oil recovery - An experimental investigation," Petrophysics, vol. 49, no. 1, pp. 28-35, 2008.

[7] J. S. Buckley and Y. Liu. (1998). Some Mechanisms of Crude Oil/brine/solid Interactions. [Online]. Available: https://www.sciencedirect.com

[8] M. B. Alotaibi, R. A. Nasralla et al., "Wettability studies using low salinity water in sandstone reservoirs," presented at Offshore Technology Conference, Houston, Texas, USA, 2010.

[9] I. Fjelde, S. M. Asen, and A. V. Omekeh, "Low salinity water flooding experiments and interpretation by simulations," in Proc. 
SPE Improved Oil Recovery Symposium, Tulsa, Oklahoma, 14-18, April 2012.

[10] R. A. Nasralla, M. A. Bataweel, H. A. Nasr-El-Din (2011). Investigation of wettability alteration and oil-recovery improvement by low-salinity water in sandstone rock. [Online]. Available: https//www.onepetro.org/Canada

[11] H. Mahani, "Kinetics of the Low Salinity Water Flooding Effect studied in a model System," in Proc. SPE Enhanced Oil Recovery Conference, Kuala Lumpur, Malaysia, 2013.

[12] A. Hamouda, "Investigating enhanced oil recovery from sandstone by low-salinity water and fluid/rock interaction," Energy Fuels, 2014.

[13] A. Aladasani, B. Bai, Y-S. Wu, "Investigating low-salinity water flooding recovery mechanisms in sandstone reservoirs," in Proc. SPE Improved Oil Recovery Symposium, Tulsa, Oklahoma, USA, 2012.

[14] A. RezaeiDoust, T. Puntervold, and T. Austad, "A Discussion of the low salinity EOR potential for a north sea sandstone field," in Proc. SPE Annual Technical Conference and Exhibition, Florence, Italy, 2010.

[15] J. S. Buckley, "Evaluation of reservoir wettability and its effect on oil recovery," 1997.

[16] E. P. Robertson, "Oil recover increases by low-salinity flooding: SPE," in Proc. Annual Technical Conference and Exhibition, Florence Italy, 2010

[17] R. A. Nasralla, M. B. Alotaibi, and H. A. Nasre-El-Din, "Efficiency of oil recovery by low salinity water flooding in sandstone reservoirs," SPE Western North American Regional Meeting held in Anchorage, Alaska, USA, 2011.

[18] G. R. Jerauld, C. Y. Lin, K. J. Webb, and J. C. Seccombe, "Modeling low salinity water flooding," in Proc. SPE Reservoir Evaluation and Engineering, 2008.

[19] Y. S. Wu and B. Bai, "Efficient simulation for low-salinity water flooding in porous and fractured reservoirs," in Proc. SPE Reservoir Simulation Symposium, Texas, 2009.

[20] A. Kazemi Nia Korrani, K. Sepehrnoori, M. Delshad, "A novel mechanistic approach for modeling low salinity water injection," in Proc. SPE Annual Technical Conference and Exhibition, Louisiana, USA, 2013.
[21] A. V. Omekeh, S. Evje, and H. A. Friis, "Modelling of low salinity effects in sandstone oil rocks," International Journal of Numerical Analysis and Modelling, 2012.

[22] E. Alagic and A. Skuage, "A combined low salinity brine injection and surfactant flooding in mixed-wet sandstone cores," Energy Fuels, 2010.

[23] K. Johannessen et al., "A low salinity water flood at reduced capillary," in Proc. SPE Improved Oil Recovery Symposium, Tulsa, USA, 2012.

[24] H. Mohammadi and G. Jerauld, "Mechanistic modelling of the benefit of combining polymer with low salinity water for enhanced oil recovery," in Proc. SPE Improved Oil Recovery Symposium Oklahoma, USA, 2012.

[25] H. Alzayer and M. Sohrabi, "Numerical simulation of improved heavy oil recovery by low-salinity water injection and polymer flooding," in Proc. SPE Annual Technical Symposium and Exhibition, Khobar, Saudi Arabia, 2013.

[26] E. C. M. Vermolen, M. Pingo-Almado, and B. M. Wassing, D. J. Ligthlm, and S. Masalmeh, "Low-salinity polymer flooding: improving polymer flooding technical feasibility and economics by using low-salinity make up brine," International Petroleum Technology Conference, Doha, Qatar, 2014.

[27] B. Shaker Shiran and A. Skauge, "Enhance oil recovery (eor) by combined low salinity water/polymer flooding," Energy \& Fuel, 2013.

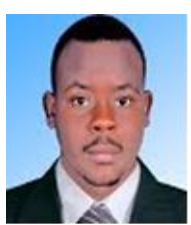

Adam Abdalla was born in 1988 in Khartoum, Sudan. In 2014. He got the BSc degree from School of Geoscience Red Sea University, Sudan. In 2015, he won scholarship from Chinese Government Scholarship, then he started studying master majoring in oil and gas field development at China University of Petroleum, China. His research interest is enhanced oil recovery by low salinity water flooding and injection of $\mathrm{CO}_{2}$ into Low Permeability Reservoir. 